\title{
Epidemiology of the first outbreak of carbapenem-resistant Klebsiella pneumoniae in Saudi Arabia
}

\author{
HH Balkhy ${ }^{1,2^{*}}$, A El-Saed ${ }^{1}$, S Al Johani ${ }^{3}$, HT Tayeb ${ }^{2}$, A Al-Qahtani ${ }^{4}$, M Alahdal $^{4}$, M Sallah ${ }^{1}$, A Alothman ${ }^{5}$, Y Alarabi $^{6}$ \\ From International Conference on Prevention \& Infection Control (ICPIC 2011) \\ Geneva, Switzerland. 29 June - 2 July 2011
}

\section{Introduction / objectives}

We describe our experience in detecting and containing the first documented CRKP outbreak in Saudi Arabia (SA).

\section{Methods}

A prospective investigation of all cases identified with carbapenem resistance during the outbreak peroid and six months prior.

\section{Results}

During March 2010, a cluster of 6 patients with CRKP was detected. Patients with CRKP were placed under strict contact isolation. Admission and periodic active surveillance cultures showed a downward trend of CRKP clinical cases over the following months to zeros in July and August. All patients had prolonged hospital stay before CRKP detection and the majority had recent history of carbapenem use (75\%), colonization/infection with other MDROs (75\%), surgical procedures $(80 \%)$, indwelling devices (83\%), and mechanical ventilation (75\%). About $33 \%$ of patients with CRKP had clinical infection and $58 \%$ died during the current hospitalization. PFGE results identified a dominant clone during the outbreak, Figure 1.

\section{Conclusion}

Infection control practices are not enough to eliminate the emergence of resistant pathogens. More active interventional methods including an antimicrobial stewardship program would be essential to combat the emergence of multidrug resistant organisms.

${ }^{1}$ Infection Prevention and Control Department, KAMC, Riyadh, Saudi Arabia Full list of author information is available at the end of the article

\section{Disclosure of interest}

None declared.

\section{Author details}

'Infection Prevention and Control Department, KAMC, Riyadh, Saudi Arabia. ${ }^{2}$ Molecular Department, King Abdullah Internatinal Medical Research Center Riyadh, Saudi Arabia. ${ }^{3}$ Clinical Pathology Department, KAMC, Riyadh, Saudi Arabia. ${ }^{4}$ King Faisal Specialist Hospital and Research Center, Riyadh, Saudi Arabia. ${ }^{5}$ Department of Medicine, KAMC, Riyadh, Saudi Arabia. ${ }^{6}$ Department of Critical Care, KAMC, Riyadh, Saudi Arabia.

Published: 29 June 2011

\section{doi:10.1186/1753-6561-5-S6-P295}

Cite this article as: Balkhy et al:: Epidemiology of the first outbreak of carbapenem-resistant Klebsiella pneumoniae in Saudi Arabia. BMC Proceedings 2011 5(Suppl 6):P295.

Submit your next manuscript to BioMed Central and take full advantage of:

- Convenient online submission

- Thorough peer review

- No space constraints or color figure charges

- Immediate publication on acceptance

- Inclusion in PubMed, CAS, Scopus and Google Scholar

- Research which is freely available for redistribution 